\title{
Influence of Dentin Desensitizers on the Bond Strength of Self-etch Adhesive to Dentin: An in vitro Study
}

\author{
${ }^{1}$ Sneha Jeetendra, ${ }^{2}$ Anithakumari Rangappa, ${ }^{3}$ Meena Naganathan, ${ }^{4}$ Vijayalakshmi Lakshminarasimhaiah
}

\section{ABSTRACT}

Aims and objectives: Hypersensitivity is a multietiological clinical problem. Many desensitizing treatments have been advocated to reduce the hypersensitivity. The aim of this study is to evaluate the effect of few in-office desensitizing agents on the bond strength of composite restoration.

Materials and methods: Forty-eight sound human premolars were used for the study. The occlusal surface of each teeth was grounded with a diamond disk to expose the flat dentin surface, polished with 120 and 320 silicon grit sand paper. The specimens were then divided into four groups $(n=12)$ based on the type of dentin desensitizing agent given. Group I was treated with Vivasens, group II was treated with MS Coat F, group III was treated with Solo Eze, and group IV served as a control where no desensitizing agent was used.

The specimens were treated with one-step self-etch and restored with composites according to the manufacturer's instructions. The specimens were then stored in distilled water for 24 hours and subjected to Universal Testing Machine to check the tensile bond strength.

Results: Statistical analysis of the data obtained revealed the mean values for the tensile bond strengths were 92.53, 71.07, $95.07,160.28 \mathrm{~N}$ for groups I to IV respectively. These values were statistically significantly different between groups pretreated with desensitizing agents as compared with control group.

Conclusion: Dentin pretreated with desensitizing agents has lower tensile bond strength with resin composites as compared with dentin that is untreated. Among the experimental groups, hydroxyethyl methacrylate (HEMA)-containing desensitizing agents had better bond strength compared with the fluoridecontaining agents.

Keywords: Desensitizing agents, Self-etch adhesive, Tensile bond strength.

How to cite this article: Jeetendra S, Rangappa A, Naganathan M, Lakshminarasimhaiah V. Influence of Dentin Desensitizers on the Bond Strength of Self-etch Adhesive to Dentin: An in vitro Study. J Oper Dent Endod 2018;3(1):18-21.

Source of support: Nil

Conflict of interest: None

\footnotetext{
${ }^{1}$ Postgraduate Student, ${ }^{2,3}$ Professor, ${ }^{4}$ Reader

${ }^{1-4}$ Department of Conservative Dentistry and Endodontics V S Dental College \& Hospital, Bengaluru, Karnataka, India

Corresponding Author: Sneha Jeetendra, Postgraduate Student, Department of Conservative Dentistry and Endodontics V S Dental College \& Hospital, Bengaluru, Karnataka, India Phone: +918025485534, e-mail: snehajchajed91@gmail.com
}

\section{INTRODUCTION}

Dentin hypersensitivity is an agonizing condition encountered in the clinical scenario. The condition can be described as following: "Dentin hypersensitivity is characterized by short, sharp pain arising from exposed dentin in response to stimuli, typically, thermal, tactile, chemical, evaporative or osmotic which cannot be ascribed to any other dental defect or pathology." ${ }^{11}$ Loss of enamel, root surface denudation and gingival recession caused by periodontal disease, periodontal treatment, and improper brushing habits result in exposure of underlying dentin to cause hypersensitivity. ${ }^{2-4}$

Hydrodynamic theory is the most widely acknowledged theory for explaining dentinal hypersensitivity, which states that pain is due to deformation of sensory nerves in the pulp, caused by peripheral stimuli transmitted by the movement of fluids or semi-fluid material in dentin tubules. ${ }^{5}$

There are several modalities with which dentin hypersensitivity can be treated. Most of the topical desensitizing agents act by nerve desensitization, forming precipitates and plugging the dentinal tubules. Postapplication of desensitizing agents, if bonded restorations to be done, there is variable report in the literature regarding the bond strength of these restorations.

Three desensitizers with different agents were selected for the study and there are no studies reported with Solo Eze in the literature. Therefore, the present study aimed to evaluate the effect of desensitizing agents on the bond strength of resin composite to dentin.

\section{MATERIALS AND METHODS}

Forty-eight human premolars free of any caries or cracks were selected for the study. Teeth were cleaned with ultrasonic scaler to remove the tissue remnants, sterilized, and placed in distilled water until use. The occlusal surface of each teeth was grounded with a diamond disk to expose the flat dentin surface. The flat dentin surface was polished using 120 and 320 grit silicon carbide paper and the polished surface was rinsed with water and was divided into four groups of 12 teeth each.

Group I: Vivasens (Ivoclar Vivadent, India) samples were treated on dentin surface for 10 seconds and dried for 10 seconds. 
Group II: MS Coat F (Sun Medical, Japan) samples were treated on dentin surface for 30 seconds, dried for 10 seconds, and rinsed.

Group III: Solo Eze (Medicept, UK) samples were treated on dentin surface for 10 seconds, waited for 30 seconds, and dried.

Group IV: No desensitizing agent was applied on the prepared dentin surfaces (control group) (Table 1).

The desensitized specimens were stored in distilled water for 1 week. Single-step adhesive (Single Bond Universal, $3 \mathrm{M}$ ) was applied on the specimens and restored with composite cylinders of $3 \mathrm{~mm}$ diameter and $5 \mathrm{~mm}$ of height in dimension (Filtek Z350XT, $3 \mathrm{M}$ ) and subjected to universal testing machine at a crosshead speed of $1 \mathrm{~mm} / \mathrm{min}$. The tensile load required for debonding was recorded in Newton.

\section{Statistical Analysis}

The recorded values were subjected to statistical analysis using the Statistical Package for the Social Sciences software (version 22.0, released 2013. Armonk, NY: IBM Corp): the intergroup analysis of the mean values of the bond strength was done using one-way analysis of variance (ANOVA) and the intragroup analysis was done using Bonferroni post hoc analysis; p-value $<0.05$ was considered to be significant in the study.

\section{RESULTS}

One-way ANOVA showed that there is significant difference in the mean bond strength values between the four groups $(\mathrm{p}<0.001)($ Graph 1$)$.

Multiple comparisons using Bonferroni post hoc analysis revealed that the control group showed significantly

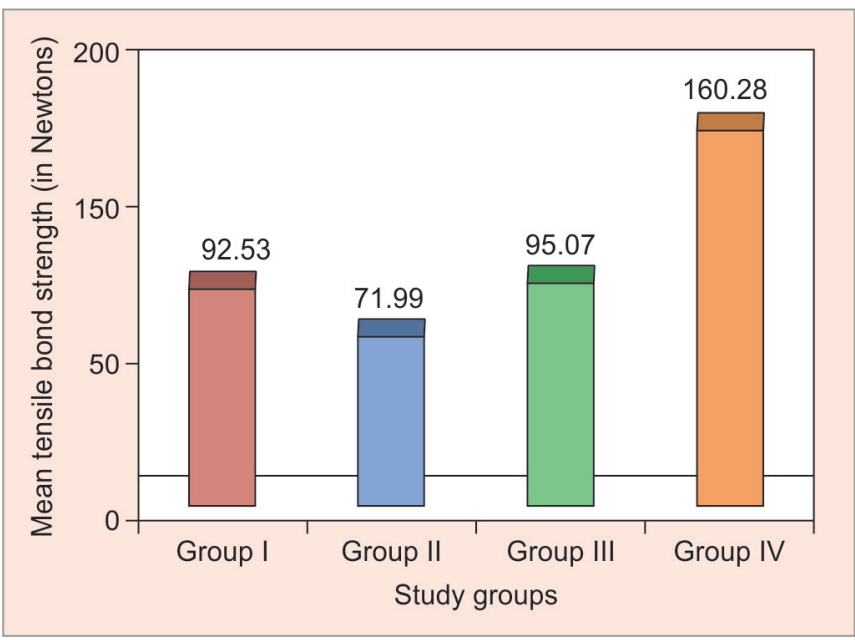

Graph 1: Comparison of mean tensile bond strength between the four study groups

higher tensile bond strength compared with Solo Eze, followed by Vivasens and MS Coat F respectively, at $\mathrm{p}<0.001$ (Table 2).

Post hoc analysis revealed that the mean bond strength of the control group is significantly higher than all the test groups (I-III), $\mathrm{p}<0.001$.

However, among the test groups, Solo Eze group showed more mean tensile bond strength values than Vivasens group and MS coat group (SoloEze $>$ Vivasens $>$ MS Coat) but the difference is not statistically significant.

\section{DISCUSSION}

Dentin, which forms the major bulk of the tooth, is traversed by dentinal tubules that extend from the pulp to the enamel-dentin or cementodentinal junction. Dentin is a highly mineralized tissue, which is permeable and it

Table 1: List of materials used

\begin{tabular}{lll}
\hline Desensitizing treatments & Manufacturer & Composition \\
\hline Vivasens & Ivoclar Vivadent & $\begin{array}{l}\text { Ethanol, water, methacrylate-modified polyacrylic acid, polyethylene glycol, } \\
\text { phosphoric acid, methacrylic acid, potassium fluoride } \\
\text { Copolymer with sulfonic acid group, oxalic acid, sodium fluoride }\end{array}$ \\
$\begin{array}{l}\text { MS Coat F } \\
\text { Solo Eze }\end{array}$ & $\begin{array}{l}\text { Sun Medical } \\
\text { Medicept }\end{array}$ & $\begin{array}{l}\text { HEMA and benzalkonium chloride } \\
\text { system }\end{array}$ \\
Filtek Z350 & $3 \mathrm{M}$ & $\begin{array}{l}\text { MPP phosphate monomer, dimethacrylate resins, HEMA, vitrebond }{ }^{\mathrm{TM}} \text { copolymer, } \\
\text { filler, ethanol, water initiators, silane }\end{array}$ \\
\hline
\end{tabular}

MDP: Methacryloyloxy-decyl-dihydrogen-phosphate; Bis-GMA: Bisphenol A diglycidyl ether dimethacrylate; UDMA: Urethane dimethacrylate; TEGDMA: Triethylene glycol dimethacrylate; Bis-EMA: Ethoxylated bisphenol-A dimethacrylate

Table 2: Comparison of mean tensile bond strength between four study groups using ANOVA by Bonferroni post hoc analysis

\begin{tabular}{|c|c|c|c|c|c|c|c|c|c|c|c|}
\hline \multirow[b]{2}{*}{ TBS } & \multirow[b]{2}{*}{$n$} & \multirow[b]{2}{*}{ Mean } & \multirow[b]{2}{*}{$S D$} & \multirow{2}{*}{$\begin{array}{l}\text { Standard } \\
\text { error }\end{array}$} & \multicolumn{2}{|c|}{$95 \%$ Cl for mean } & \multirow[b]{2}{*}{ Min } & \multirow[b]{2}{*}{ Max } & \multirow[b]{2}{*}{$p$-value } & \multirow[b]{2}{*}{ Sig. diff } & \multirow[b]{2}{*}{$p$-value } \\
\hline & & & & & Lower & Upper & & & & & \\
\hline Vivasens & 12 & 92.53 & 18.79 & 5.42 & 80.59 & 104.46 & 67.79 & 124.97 & $<0.001^{*}$ & $\begin{array}{l}\mathrm{V} \text { vs } \mathrm{M}, \mathrm{V} \text { vs } \mathrm{S} \\
\text { and } \mathrm{V} \text { vs } \mathrm{C}\end{array}$ & $0.64,1.00$ and $<0.001^{*}$ \\
\hline MS Coat F & 12 & 71.99 & 28.16 & 8.13 & 54.10 & 89.88 & 32.9 & 125.43 & & $\begin{array}{l}\mathrm{M} \text { vs } \mathrm{S} \text { and } \mathrm{M} \\
\text { vs } \mathrm{C}\end{array}$ & 0.43 and $<0.001^{*}$ \\
\hline Solo Eze & 12 & 95.07 & 21.53 & 6.22 & 81.38 & 108.75 & 65.45 & 126.03 & & $\mathrm{~S}$ vs $\mathrm{C}$ & $<0.001^{*}$ \\
\hline Control & 12 & 160.28 & 46.01 & 13.28 & 131.05 & 189.51 & 107.49 & 265.11 & & & \\
\hline
\end{tabular}

$$
\text { *p-value }<0.001
$$


can get exposed by dental caries or restorative procedures. Once the dentin is exposed, it causes sensitivity and the dentinal fluid within its tubules can affect the bonding properties of restorative materials.

Noncarious cervical lesions like attrition, abrasion, abfraction, and erosion contribute to enamel and cementum loss, exposing dentinal tubules to the oral cavity and thus causing hypersensitivity. In addition, gingival recession is also known to attribute to sensitivity. ${ }^{6}$

Dentinal hypersensitivity is treated using different desensitizing agents. However, these agents may influence the bond strength during restoration, thus affecting the durability of these restorations.

The present study aimed to evaluate the influence of different in-office desensitizing agents on the tensile bond strength of adhesive restoration.

All the experiment groups achieved lesser bond strength compared with the control group, this is in agreement with studies conducted by Seara et $\mathrm{al}^{7}$ and Awang et al. ${ }^{8}$

Desensitizers results in blocking the intertubular diffusion channels and tubules orifices. They physically or chemically prevent the complete resin penetration through the demineralized dentin, thus decreasing the bond strength. The present study showed Solo Eze group produced highest bond strength. It contains HEMA and benzalkonium chloride.

Hydroxyethyl methacrylate is a water-soluble monomer present in dentin adhesives and desensitizing agent. It is known to improve infiltration of the partially demineralized dentin mainly because of its hydrophyllic nature and the presence of ester and hydroxyl functional groups. ${ }^{9}$

Because of its role in facilitating diffusion of resin monomer into the partially demineralized collagen network, HEMA is considered as an adhesion promoter. ${ }^{10}$

The bonding agent (single universal bond) also contains HEMA. So, the desensitizing agent containing HEMA and the bonding agent containing HEMA produces an acidic effect twice on the dentin resulting in better penetration of bonding agents, which results in achieving a higher bond strength. ${ }^{12}$

Vivasens achieved lower bond strength than Solo Eze and MS Coat F had the lowest bond strength. Both of these agents have fluoride contents as one of the components, potassium fluoride in Vivasens and sodium fluoride in MS Coat F.

Fluoride-containing desensitizing agents form precipitates of insoluble calcium fluoride. ${ }^{2}$ The precipitation of calcium fluoride microcrystals and mineral deposits into dentinal tubules prevents resin infiltration. Resin tag formation is known to increase resin-dentin bond strength. ${ }^{7,11}$
Paes Leme et $\mathrm{al}^{12}$ conducted a scanning electron microscopy study to evaluate the occluding effect of different desensitizing agents on human dentin tubule. The authors reported deposition of fluoride and insoluble salts blocking and reducing the lumen of dentinal tubule.

This tubule occlusion prevents complete penetration of the resin component of bonding system. The lowest bond strength of MS Coat F among the experimental group could be because of the presence of sodium fluoride at a concentration of 3000 ppm. $^{13}$

\section{CONCLUSION}

To conclude, all desensitizing agents resulted in lower bond strength values. The HEMA-containing desensitizing agent resulted in higher bond strength than fluoridecontaining groups. Further clinical studies are required to illuminate this research.

Under the limitations of the present in vitro study, the results cannot be directly extrapolated to clinical situation in the absence of dentinal fluid in the extracted teeth. Further clinical studies are required to confirm these results.

\section{REFERENCES}

1. Makkar S, Goyal M, Kaushal A, Hegde V. Effect of desensitizing treatments on bond strength of resin composites to dentin—an in vitro study. J Conserv Dent 2014 Sep;17(5): 458-461.

2. Arisu HD, Dalkihç E, Üçta li MB. Effect of desensitizing agents on the microtensile bond strength of a two-step selfetch adhesive to dentin. Oper Dent 2011 Mar-Apr;36(2): 153-161.

3. Dababneh RH, Khouri AT, Addy M. Dentine hypersensitivity: dentine hypersensitivity—an enigma? A review of terminology, mechanisms, aetiology and management. Br Dent J 1999 Dec;187(11):606-611.

4. Walters PA. Dentinal hypersensitivity: a review. J Contemp Dent Pract 2005 May;6(2):107-117.

5. Akca T, Yazici AR, Celik C, Özgünaltay G, Dayangaç B. The effect of desensitizing treatments on the bond strength of resin composite to dentin mediated by a self-etching primer. Oper Dent 2007 Sep-Oct;32(5):451-456.

6. Pathan AB, Bolla N, Kavuri SR, Sunil CR, Damaraju B, Pattan SK. Ability of three desensitizing agents in dentinal tubule obliteration and durability: an in vitro study. J Conserv Dent 2016 Jan;19(1):31-36.

7. Seara SF, Erthal BS, Ribeiro M, Kroll L, Pereira GD. The influence of a dentin desensitizer on the microtensile bond strength of two bonding systems. Oper Dent 2002 Mar-Apr;27(2): 154-160.

8. Awang RA, Masudi SM, MohdNor WZ. Effect of desensitizing agent on shear bond strength of an adhesive system. Arch Orofac Sci 2007;2:32-35.

9. Xu J, Stangel I, Butler IS, Gilson DF. An FT-Raman spectroscopic investigation of dentin and collagen surfaces modified by 2-hydroxyethylmethacrylate. J Dent Res 1997 Jan;76(1): 596-601. 
10. Van Meerbeek B, Yoshida Y, Lambrechts P, Vanherle G, Duke ES, Eick JD, Robinson SJ. A TEM study of two waterbased adhesive systems bonded to dry and wet dentin. J Dent Res 1998 Jan;77(1):50-59.

11. Sengun A, Koyuturk AE, Sener Y, Ozer F. Effect of desensitizers on the bond strength of a self-etching adhesive system to caries-affected dentin on the gingival wall. Oper Dent 2005 Jul-Aug;30(4):430-435.

12. Paes Leme A, dos Santos JC, Giannini M, Wada RS. Occlusion of dentin tubules by desensitizing agents. Am J Dent 2004 Oct;17(5):368-372.

13. Sun Medical. Available from: www.Sunmedical. 